\title{
Underuse of Primary Care in China: The Scale, Causes, and Solutions
}

\author{
Dan Wu, MSc, and Tai Pong Lam, MD, PhD
}

Strengthening the primary care system and promoting utilization of primary care are the major targets of China's ambitious health reforms to meet its people's escalating health care needs. However, the changing trend of primary care utilization 4 years before and after 2009, when the health reforms started, is against the government's stated goal. The percentage of outpatient visits in primary care significantly declined from $63 \%$ in 2005 to $59 \%$ in $2013(P=.002)$. In Western China it went down from $66 \%$ in 2010 to $62 \%$ in $2013(P=.017)$ and slightly dropped in Eastern and Central China. Causes are multiple and include major historic and institutional factors such as severe maldistribution of human resources and lack of primary care practitioners (PCPs), lack of a functional gate-keeping mechanism, the low educational attainment of PCPs, and the detrimental elements of health reforms. Immediate measures need to be taken to improve the situation. These include taking irrational hospital expansion under strict control through enhancing the government's accountability for health care industry regulation, strategies to recruit and retain a quality primary care workforce, empowering PCPs as gatekeepers in the system, timely evaluation of the impact of health reforms on primary care, and modifying damaging policies. ( $\mathrm{J}$ Am Board Fam Med 2016;29:240-247.)

Keywords: Access to Health Care, China, Health Care Reform, Primary Health Care

China, home to one fifth of the world's population, has since 2000 had an escalating trend toward an aging society. ${ }^{1}$ A noncommunicable disease (NCD) spectrum, where $80 \%$ of all deaths are caused by cerebro-/cardiovascular diseases, chronic obstructive pulmonary disease, and cancers, ${ }^{2}$ challenges the country's capacity to meet its soaring health care needs, compounded by worrying environmental pollution and its consequent health problems. To meet its healthcare needs efficiently, the nation cannot afford to ignore a good primary care system. Good primary care can improve population health outcomes, including reduced all-

This article was externally peer reviewed.

Submitted 13 May 2015; revised 9 September 2015; accepted 22 September 2015.

From the Department of Family Medicine and Primary Care, Faculty of Medicine, The University of Hong Kong, Hong Kong.

Funding: none.

Conflict of interest: none declared.

Corresponding author: Tai Pong Lam, Department of Family Medicine and Primary Care, University of Hong Kong, 3/F Ap Lei Chau Clinic, 161 Main Street, Ap Lei Chau, Hong Kong (E-mail: tplam@hku.hk). cause mortality, lower incidence of low birth weight, and lower rates of poor self-reported health and lifestyle risk factors (eg, obesity and smoking). ${ }^{3}$ In fact, it is China's "barefoot doctor" system that has been a successful primary health care (PHC) model for other low- and middleincome countries and inspired the global primary care campaign of Alma Ata in $1978 .^{4}$ In China, farmers in the rural sector with secondary education were trained for 3 to 6 months by urban physicians to meet the health needs of the sizable number of rural inhabitants, accounting for $80 \%$ of the whole population during the Cultural Revolution. ${ }^{5,6}$ Applying both Western and local remedies, barefoot doctors provided universal basic medical care and public health services. It remarkably improved population health at a very low cost. ${ }^{7,8}$

People's Republic of China built a 3-tier health care system after its foundation in 1949. Primarylevel facilities (including community health facilities in urban areas, township health centers, and village clinics in the rural areas) provide preventive 
and basic medical services, whereas secondary and tertiary hospitals provide specialized care. Nevertheless, the government was less financially supportive of health care industry and has held less accountability since the economic reform in the 1980s. The barefoot doctor model was gradually dismantled when a shift in funding from primary health care to hospital-based care occurred; this led to the proliferation of specialized care in hospitals. ${ }^{9}$ To ensure access to basic medical services for all, fees for services have been set lower than costs at all government-run facilities. ${ }^{10}$ The government subsidized only $10 \%$ of hospital revenue $^{11}$ but allowed a markup of $15 \%$ on drugs and high-tech tests so facilities could survive. ${ }^{12}$ Medical practices became profit-driven entities, and hospitals competed for patients with primary care facilities. To make matters worse, hospitals tended to expand their own scale and services to attract more patients-and thereby more profits-without proper government regulations. ${ }^{11} \mathrm{~A}$ fragmented health system, rising medical costs, and wasteful health care delivery occurred, and they remain enormous challenges that the system is trying to tackle through ambitious health reforms launched in 2009. ${ }^{13}$ The recent reforms prioritize the development of good primary care based on the existing framework. ${ }^{14}$ All levels of government have poured resources into primary care infrastructure construction, personnel training, and other supporting programs, including salary reforms, a zero-profit drug policy (a limited number of essential medicines), and insurance schemes at the primary care level. ${ }^{15}$ However, the investment does not seem to be leading to a successful primary care system. ${ }^{13}$

This article discusses the huge challenge the Chinese health care system is facing: the underuse of primary care. It first elaborates the scale of the problem nationally, with regional comparisons. The causes, including some historic and institutional factors, are then discussed. It concludes with some solutions for the healthy development of primary care in the country. Underutilization of primary care, the shortage of young primary care practitioners (PCPs), and difficulty recruiting and retaining doctors in primary care are similar challenges facing the United States. ${ }^{16}$ Primary care issues between the 2 countries are compared. As China's barefoot doctor system provided a successful primary care model for other underdeveloped countries, this article is also relevant to many other parts of the world.

\section{Underuse of Primary Care}

Promoting primary care is a major target of the latest health reforms initiated in China in 2009. Central and local health authorities have invested many resources. There was a dramatic increase (by $33 \%$ ) in outpatient throughput from 2009 to 2013, with varying degrees of increase in the number of patients visiting all types of facilities. ${ }^{17}$ There is, however, no convincing evidence of a shift of patient flow from higher-level hospitals to primary care facilities. ${ }^{15}$ Figure 1 shows the changing trend of outpatient visits (by percentage) in different types of health facilities between 2005 and 2013. ${ }^{17,18}$ The underuse of primary care services was staggering before the reforms, and remains so after. Unexpectedly, there was even a statistically significant decrease $(P=.002)$ in the percentage of visits to primary care, from $63 \%$ (2.59 billion of 4.10 billion total visits) to $59 \%$ (4.32 billion of 7.31 billion total visits), whereas hospital visits increased from $34 \%$ to $37 \%(P=.003)$. The use of primary care is far from the $\geq 80 \%$ recommended by the World Health Organization ${ }^{19}$ but is close to the rate of $51 \%$ in the United States, ${ }^{20}$ where the most expensive medical care exists but not the best population health. ${ }^{21}$

Changing trends in patient visits to different levels of facilities by region from 2009 to 2013 are shown in Table 1. China is geographically divided into the eastern, central, and western parts, according to China Statistics Yearbooks. Primary care utilization experienced a slight reduction in Eastern and Central China, but the differences are not significant. In Western China utilization went down from $66 \%$ in 2010 to $62 \%$ in $2013(P=.017)$. Visits to hospitals increased significantly in both Eastern (from 39\% to $42 \%$; $P=.016$ ) and Western China (from 31\% to $35 \% ; P=.01)$. Central China saw a $1 \%$ increase in hospital visits, which is not a significant difference. A few studies also identified the problem from the perspective of service users. In a 2013 study in Fuzhou, in Eastern China, hospitals were rated highest in first-contact utilization by patients, against community health facilities, ${ }^{22}$ echoing an earlier study that $>76 \%$ of 5229 patients with NCDs were diagnosed by secondary 
Figure 1. Changing trend in the percentage of outpatient visits, by type of facility, from 2005 to 2013 in China. Sources: China Health Statistics Yearbooks 2011 to 2014.

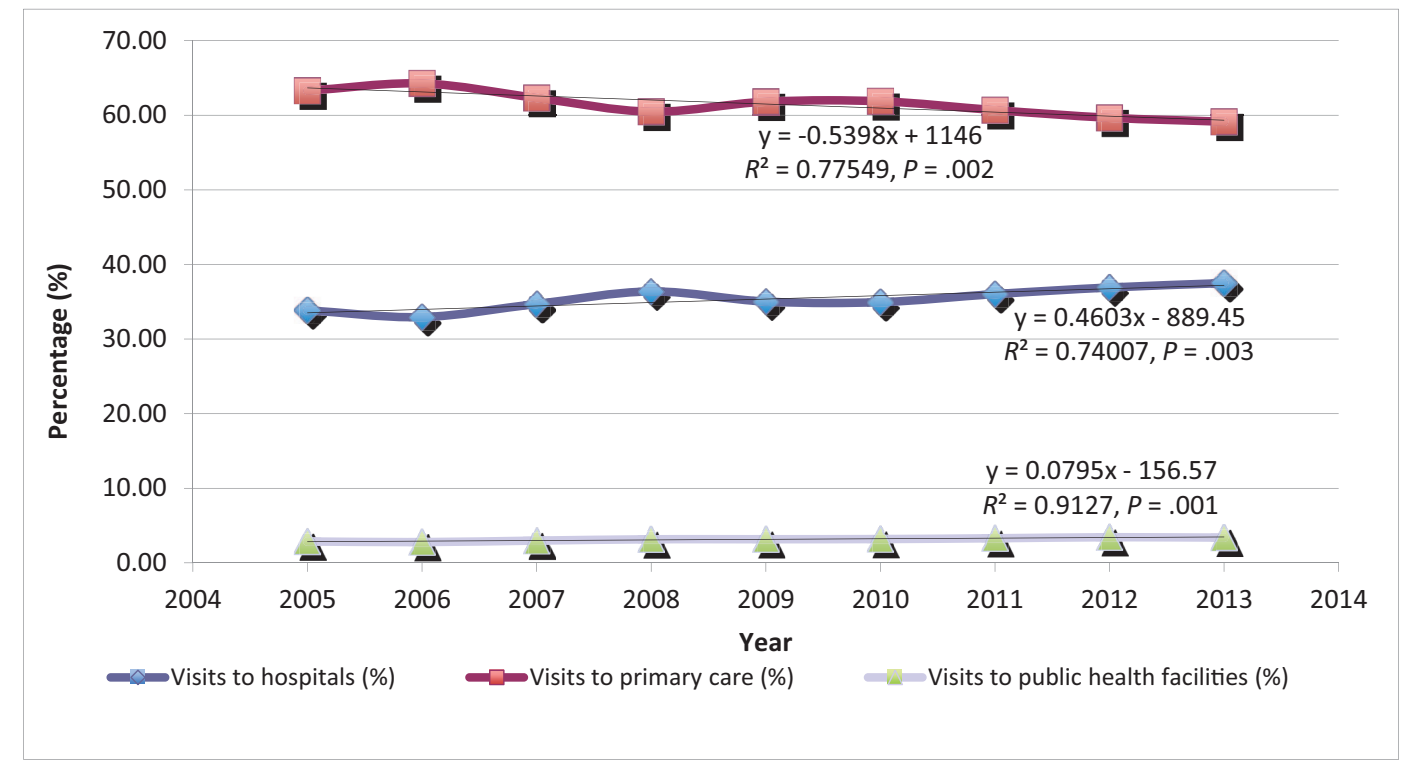

or tertiary health care facilities, and $53 \%$ preferred higher-level facilities for follow-up management. These trends are simply against the goal of promoting the use of primary care.

During the same period, all-cause mortality, disparity in health, and health expenditures were worsening. ${ }^{17}$ All-cause mortality increased from $0.651 \%$ in 2005 to $0.716 \%$ in 2013 . Infant mortality rate in rural areas was more than 2 -fold that in urban cities in 2005 and went up and down afterward. Total health expenditure per capita has significantly increased from RMB662 to 2327 (US\$101-354), with a significant increase in copayments as well. ${ }^{17}$ Affordability for the poorer rural households is getting worse, compared with their urban counterparts. ${ }^{23}$

\section{Causes}

The underutilization of primary care is dramatic all over the country, and in general it got worse after the health reforms. Causes are multiple and include major historic and institutional factors such as severe maldistribution of quality human resources, low educational attainment of PCPs and the public's lack of trust in the quality of primary care, lack of a gatekeeping function by PCPs, and the detrimental elements of health

Table 1. Outpatient Visits to Three Types of Facility, by Region, from 2009 to 2013

\begin{tabular}{llcccccc}
\hline Region & Type of Facility & 2009 & 2010 & 2011 & 2012 & 2013 & $P$ Value \\
\hline \multirow{2}{*}{ Eastern China } & Hospital & $1064(39)$ & $1148(39)$ & $1285(41)$ & $1438(41)$ & $1547(42)$ & .016 \\
& Primary care & NA & $1663(57)$ & $1754(56)$ & $1914(55)$ & $2036(55)$ & .056 \\
& Others & NA & $96(3)$ & $109(3)$ & $125(4)$ & $128(3)$ & .742 \\
Central China & Hospital & $439(31)$ & $455(30)$ & $494(30)$ & $558(31)$ & $600(32)$ & .319 \\
& Primary care & NA & $1021(67)$ & $1095(67)$ & $1173(66)$ & $1226(65)$ & .056 \\
& Others & NA & $45(3)$ & $49(3)$ & $57(3)$ & $59(3)$ & .193 \\
\multirow{2}{*}{ Western China } & Hospital & $419(31)$ & $436(31)$ & $480(32)$ & $546(34)$ & $595(35)$ & .01 \\
& Primary care & NA & $927(66)$ & $957(64)$ & $1022(63)$ & $1062(62)$ & .017 \\
& Others & NA & $46(3)$ & $49(3)$ & $56(3)$ & $61(4)$ & .225 \\
\hline
\end{tabular}

Data are million visits (\%).

Source: China Health Statistics Yearbooks 2010 to 2014. 
reform policies. These 5 factors do not operate independently, yet they are complexly related to each other. Boosts to the economy and the fast development of the public transportation system in the country are also contributing to patient flow between different areas. These are taken into consideration as the contextual background for the discussion of the above-mentioned factors.

\section{Maldistribution of Human Resources and Lack of PCPS}

A salient maldistribution of human resources among different levels of health facilities and the lack of PCPs are the most important contributors. Since the inception of health reforms, the unreasonable expansion of secondary and tertiary hospitals has not been controlled. For example, an aircraft carrier-sized hospital in Henan Province is currently under construction. This hospital is equipped with 5000 hospital beds and will expand to $\sim 8000$ beds in $2016 .{ }^{24}$ Such an example is only the tip of the iceberg. Among 23,170 hospitals, over $10 \%$ had $>500$ hospital beds in 2012, with $4.5 \%$ equipped with $>800$ beds. ${ }^{17}$ This draws quality health workers away from primary care in a system where most medical professionals consider working in hospitals as a better career path with better pay and higher social status. ${ }^{25,26}$ Less than $30 \%$ of medical graduates are willing to choose primary care. ${ }^{27-29}$ Currently, only $38 \%$ of licensed doctors and $21 \%$ of registered nurses are working in primary care $^{17}$ (Table 2).

This rather grim picture was not painted overnight. Since the economic reform in the 1980s, the so-called public facilities have been profit-driven, and resources are centered in hospitals. ${ }^{30,31}$ This contributed to the shortage of quality workforce at the primary level. A better trained type of PCP is called a general practitioner (GP). According to the

Table 2. Distribution of Licensed Doctors and Registered Nurses by Type of Facility in 2013

\begin{tabular}{lcc}
\hline & Doctors & Nurses \\
\hline Hospitals & $1,503,184(54)$ & $2,041,367(73)$ \\
Primary care & $1,050,067(38)$ & $576,630(21)$ \\
Public health/others & $241,503(8)$ & $165,124(6)$ \\
Total & $2,794,754(100)$ & $2,783,121(100)$ \\
\hline
\end{tabular}

Data are n (\%).

Source: China Health Statistics Yearbook 2014. national directive released in 2011, 300,000 GPs will be needed to meet its stated goal of providing 2 to 3 GPs for every 10,000 population by $2020 .^{32}$ In 2013, however, the average number of GPs per 10,000 population was 1.07 , with the lower-income parts of China having $>1 .{ }^{17}$ So, there is a shortage of at least 130,000 GPs, and nearly 650 million Chinese do not have access to proper GPs. The United States faces similar challenges. ${ }^{16}$ The US health system is specialist-driven, with $70 \%$ of practitioners being specialists. Of Americans, 20\% do not have adequate access to primary care because of a shortage of practitioners, and only $7 \%$ of medical graduates choose a career in primary care. ${ }^{16,33}$ Both nations lag behind other developed countries in the ratio of PCPs to specialists, which is approximately $50 \%$ in Canada and Western Europe. $^{32}$

\section{Inadequate Formal Medical Education of PCPS}

PCPs are regarded as being poorly medically educated overall and therefore providing an inferior quality of care. ${ }^{34}$ In China, various medical education programs are in place to train medical practitioners to meet its sizable population's increasing health demands. ${ }^{35}$ Three-year (postsecondary diploma) and 5 -year (bachelor) programs are the most common forms.

Table 3 shows the educational level of PCPs in China in 2013. ${ }^{17}$ Formal medical educational level of PCPs varied greatly. Over $76 \%$ of PCPs at community health facilities in urban areas obtained a postsecondary diploma or a higher degree, compared with $55 \%$ in township health centers in rural towns. Rural village clinics were equipped with the poorest workforce, with only $20 \%$ being licensed doctors serving half of the country's population. ${ }^{17}$ The vast majority of practitioners practicing in rural clinics were converted from barefoot doctors without any formal medical education. Up to $95 \%$ of village practitioners received secondary vocational education or less, compared with $41 \%$ at township health centers in rural towns and $20 \%$ at community health facilities in urban cities. This compares to only $10 \%$ in higher-level facilities. ${ }^{17}$ Lack of trust in PCPs is a major reason for the public not favoring them as first contacts for care for undiagnosed illnesses. ${ }^{22}$

\section{Lack of a Gatekeeping Function by PCPS}

The gatekeeping role of GPs has emerged in many countries. ${ }^{36}$ Gatekeeping is more cost-effective in 
Table 3. Education Level of Primary Care Practitioners by Type of Health Facility in China in 2013

\begin{tabular}{lcccc}
\hline & \multicolumn{3}{c}{ Licensed Doctors or Assistant Doctors } & Village Practitioners \\
\cline { 2 - 4 } Education level & THCs & CHCs and CHSs & Village Clinics & 0.7 \\
\hline Bachelor's degree or higher & 11.9 & 37.1 & 15.0 & 0.1 \\
Postsecondary diploma & 43.3 & 39.5 & 79.8 & 4.6 \\
Secondary vocational school & 40.7 & 20.3 & 4.5 & 81.4 \\
High school or less & 4.1 & 3.1 & & 13.9 \\
\hline
\end{tabular}

Data are percentages.

Source: China Health Statistics Yearbook 2014.

$\mathrm{CHC}$, community health center (in urban cities); CHS, community health station (satellite clinic affiliated with community health centers in urban cities); THC, township health center (in rural areas).

delivering ambulatory care than nongatekeeping systems in Organisation for Economic Co-operation and Development countries. ${ }^{37,38}$ It ensures equity by rationing resource allocation and facilitates the provision of more comprehensive coordinated care, like in the United Kingdom. ${ }^{38,39}$ In China, the popular statement among the general public that "it is difficult and expensive to see a doctor" creates a mainstream but distorted understanding of the health care system. Fundamentally, the absence of primary care gatekeeping, weak coordinated care, and a lack of an effective referral system $^{40}$ are challenges for establishing a strong primary care system and tackling the problem of wasteful health care delivery in China. ${ }^{41}$ Primary care facilities do not have control over access to higher-level care. In a fragmented system, many patients self-refer themselves to specialists, who are often in tertiary hospitals, which are deemed to be equipped with better resources and have better quality of care even for common, simple conditions. ${ }^{10}$ A 2012 study found up to $83 \%$ of doctors said patients bypassed primary care to higher-level facilities for minor conditions. ${ }^{10}$ Some cities are experimenting with financial incentives, such as higher reimbursement rates at the primary level, or introducing a contract approach on a voluntary basis, but the long-term effects remain to be seen. Rising public demand for quality care further complicates the picture, contributed to by economic growth, environmental problems, an aging population, and better affordability of care after universal insurance coverage. Interestingly, the gatekeeping role of PCPs in the United States was short-lived during the 1990s and has been in decline since. ${ }^{42-44}$

Hospital outpatient services in China are, in fact, similar to specialist clinics in other countries. Many
Chinese patients do not have a regular physician and frequently shop around. Doctor shopping behaviors jeopardize continuity of care. The shopping process incurs iatrogenic health risks and compromised quality of care. ${ }^{33}$ Seeing multiple doctors contributes to a higher likelihood of unnecessary diagnostic tests, medical interventions, adverse events, worse outcomes, and higher medical costs. ${ }^{45}$ Lack of public awareness of the potential risks and the importance of continuity of coordinated care may be another important attribute. ${ }^{3,46-48}$ In other words, to promote primary care utilization, we cannot ignore educating the public about the potential risks of doctor shopping and the significance of primary care.

\section{Detrimental Elements of Health Reforms}

The government introduced fixed salaries for primary care facilities, which guaranteed a basic income for PCPs. The zero-profit drug policy forbade any profits from drugs, and only a limited number of cheaper but equally effective drugs were permitted for use by PCPs. ${ }^{15}$ It seemingly removed perverse incentives to overprescribe. Universal insurance coverage also improved the affordability of health services and increased utilization rates of health services. However, evidence demonstrates detrimental effects of some reform policies on the primary care workforce and primary care utilization. $^{45}$ A fixed income was generally popular among health workers in relatively poor areas because, before the reforms, the salary was lower and irregular, but this caused disincentives in better-off places because of the loss of drug profits. However, with increased workload caused by more patient visits, the salary levels set by the government have been regarded as unfair by many PCPs. ${ }^{45}$ The consequent disillusionment has led to a "brain 
drain" from primary care facilities, even in rural areas despite the income being considered secure there. In addition, because the salary is guaranteed and seeing more patients does not necessarily increase the income, some PCPs lose the motivation to see more patients and shuffle patients to higherlevel facilities. If they are insured and affected by the unavailability of certain drugs, ${ }^{49}$ patients may be more likely to bypass primary care to hospitals.

\section{Conclusion}

Immediate actions need to be taken to improve the stagnant situation of primary care in China. Taking a laissez-faire hospital expansion under strict control is imperative to break the vicious circle. Lack of governmental accountability and the absence of its leading role in regulating the health industry on a macro level have been criticized. ${ }^{15}$ The government has realized this and has started to take initiative. An urgent directive on the fast expansion of public hospitals was issued in $2014,{ }^{50,51}$ calling for a stop to irrational expansion. The National Health and Family Planning Commission (previously called the Ministry of Health) also drafted in 2014 a national health care system planning outline aiming to balance resources between different facilities and locations. $^{52}$

While implementing massive GP training programs, ${ }^{53}$ related authorities should consider how to retain these quality workforces in primary care. In some places many GP trainees do not stay in primary care but leave the program halfway through or end up being subspecialty specialists instead. ${ }^{54}$ Addressing unreasonably low pay, perceived low social status and little respect from patients, and a lack of opportunities to update new knowledge and get promoted may provide remedies. ${ }^{55}$ What is more important is that primary care education should be placed as a core component of the overall medical curriculum, serving to promote the prospectus of working as a PCP among medical professionals and students.

Empowering PCPs as gatekeepers and imposing a certain level of community control over the point of entry into the health care system are worth consideration. The Central Government has proposed that PCPs be gatekeepers since the reforms in 2009, and various cities-for example, Beijing and Shanghai-are trying to implement this policy. Nevertheless, the impact seems to be minimal. Ob- viously, these massive health reforms affecting providers in the past few years generally do not alter patients' health-seeking behaviors. Reasons have been found to be related to the severity of disease as perceived by the patient, a lack of trust in PCPs, low awareness of self-care and the presence of community health services, concerns about medical equipment, and the status of medical insurance coverage. ${ }^{10,55}$ The public's utilization pattern has a strong relationship with their own health beliefs. ${ }^{22,56}$ To form an efficient gatekeeping mechanism and a referral system, establishing a strong primary care workforce that can provide highquality professional services and proper health education campaigns to the general public are essential for such reforms to be readily acceptable. Particular attention can be paid to self-care for simple conditions, the awareness of hazards incurred with doctor shopping, aggressive tests or medical interventions, and the importance of continuous and coordinated care. ${ }^{57}$

Reform policies should be tailored to context rather than one-size-fits-all strategies for a country with huge regional socioeconomic differences. $\mathrm{Al}$ though there is still inadequate evidence of the impact of comprehensive reform on primary care, some negative consequences have started to occur in some places. Promptly refining health reform policies based on scientific evaluation of the program according to local conditions is recommended. Essentially, as the old Chinese proverb "more haste, less speed" indicates, the system should allow more time for these to proceed, because systemic improvements will inevitably take long time and are unlikely to be achieved overnight. Evidence-based policy decisions are the key to success.

\section{References}

1. Xie A. The current status of aging society, changing trends and its features in China. Stat Res 2004;8: $50-3$.

2. A comprehensive global monitoring framework and voluntary global targets for the prevention and control of NCDs. WHO discussion paper. Geneva: World Health Organization; 2011. Available from: http://www.who.int/nmh/events/2011/consultation_ dec_2011/WHO_Discussion_Paper_FINAL.pdf. Accessed April 7, 2014.

3. Starfield B, Shi L, Macinko J. Contribution of primary care to health systems and health. Milbank Q 2005;83:457-502. 
4. Weiyuan C. China's village doctors take great strides. Bull World Health Organ 2008;86:914-5. Available from: http://www.who.int/bulletin/volumes/ 86/12/08-021208.pdf. Accessed March 10, 2015.

5. Zhang DQ, Unschuld PU. China's barefoot doctor: past, present, and future. Lancet 2008;372:1865-7.

6. Liu Y. The essential of primary health care and a review of its development in china. Chin Health Econ 2007;26:11-5.

7. Blumenthal D, Hsiao W. Privatization and its discontents-the evolving Chinese health care system. N Engl J Med 2005;353:1165-70.

8. Kong XZ, ed. Chapter 9. In: China's three dimensional of agroissues prospects report [in Chinese]. Beijing: China Modern Economic Publishing House; 2009.

9. Wang H, Gusmano MK, Cao Q. An evaluation of the policy on community health organizations in China: will the priority of new healthcare reform in China be a success? Health Policy 2011;99: $37-43$.

10. Wu D, Wang Y, Lam KF, Hesketh T. Health system reforms, violence against doctors and job satisfaction in the medical profession: a cross-sectional survey in Zhejiang Province, Eastern China. BMJ Open 2014;4:e006431.

11. Luo L. zhongguo gong li yi yuan gai ge: guan zhu yun xing ji zhi he zhi du huan jing. Shanghai: Fu Dan Da Xue Chu Ban She; 2010.

12. Hesketh T, Zhu WX. Health in China: the healthcare market. BMJ 1997;314:1616-8.

13. Yip $W$, Hsiao $W$. Harnessing the privatisation of China's fragmented health-care delivery. Lancet 2014;384:805-18.

14. Chen Z. Launch of the health-care reform plan in China. Lancet 2009;373:1322-4.

15. Yip WC-M, Hsiao WC, Chen W, Hu S, Ma J, Maynard A. Early appraisal of China's huge and complex health-care reforms. Lancet 2012;379: 833-42.

16. Sanders B. Primary care access. Washington, DC: U.S. Senate Committee on Health, Education, Labor \& Pensions; 2013.

17. National Health and Family Planning Commission PRC. China health statistics yearbook 2014. Beijing: National Health and Family Planning Commission of the People's Republic of China; 2014.

18. National Health and Family Planning Commission PRC. China health statistics yearbook 2011. Beijing: National Health and Family Planning Commission of the People's Republic of China; 2011.

19. Xu J, Zhuang X. The quality of community doctors and community health services. Chin Prim Health Care 2013;18:76.

20. The number of practicing primary care physicians in the United States. Primary care workforce facts and stats no. 1. Rockville, MD: Agency for Healthcare Quality and Research; 2014. Available from: http:// www.ahrq.gov/research/findings/factsheets/primary/ pcwork1/index.html. Accessed March 9, 2015.

21. Starfield B. Is US health really the best in the world? JAMA 2000;284:483-5.

22. McCollum R, Chen L, ChenXiang T, et al. Experiences with primary healthcare in Fuzhou, urban China, in the context of health sector reform: a mixed methods study. Int J Health Plann Manage 2014;29:e107-26.

23. Long Q, Xu L, Bekedam H, Tang S. Changes in health expenditures in China in 2000s: has the health system reform improved affordability. Int J Equity Health 2013;12:40.

24. The First Affiliated Hospital of Zhengzhou University. An introduction to the hospital. 2015. Available from: http://fcc.zzu.edu.cn/s_lan1.htm. Accessed March 9, 2015.

25. China Net. Ongoing health reforms: the expansion of hospitals holds the reforms back. August 20, 2014. Available from: http://yy.china.com.cn/new/sd/ppbgt/ 130961.html. Accessed March 9, 2015.

26. Wang X, Zhao M. An exploration of medical students' career choices. J Binzhou Vocational Coll 2009;6:16-9.

27. Huang J. The study of medicos' willingness to work in basic-level medical organization in Sichuan Province. Med. and Philos. 2010;7:28-9

28. Zhang J, Zhou M, Wu L, et al. A study on influencing factors of medical undergraduates' willingness to work in basic-level medical organization. Chin Health Serv Manage. 2013;30:206-7, 226.

29. Zhong Z. A study on medical graduates' willingness to choose primary care career. J Gannan Med Univ 2011;5:733-34

30. Zhou Z. PPP: a new model of financing for funding medical services. Hosp Manage Forum 2015;32:3.

31. Huang C. The National Health Center: a mirror of the imbalance in the health system structure. Nanjing: Zhu Nin Jian Kang; 2015.

32. The State Council. A directive on establishing the general practitioner system by the State Council. Beijing: The Central People's Government, PRC. 2011. Available from: http://www.gov.cn/zwgk/201107/07/content_1901099.htm. Accessed August 6, 2015.

33. Bodenheimer T, Pham HH. Primary care: current problems and proposed solutions. Health Aff (Milwood) 2010;29:799-805.

34. Yuan J, Di Y, Wang J, Yang B, Chang J, Meng Q. Analysis on scores of medical knowledge test in grass-roots health workers. Chin J Public Health 2012;28:815-6.

35. Xu D, Sun B, Wan X, Ke Y. Reformation of medical education in China. Lancet 2010;375:1502-4.

36. Boerma WGW, Dubois C-A. Mapping primary care across Europe. In: Saltman RB, Rico A, Boerma W, eds. Primary care in the driver's seat? Organizational reform in European primary care. European Observatory on heath systems and policy series. New York: 
Open University Press, World Health Organization; 2006:22-49. Available from: http://www.euro.who. int/_data/assets/pdf_file/0006/98421/E87932.pdf. Accessed January 14, 2016.

37. Anderson GF, Hurst J, Hussey PS, Jee-Hughes M. Health spending and outcomes: trends in OECD countries, 1960-1998. Health Aff (Millwood) 2000; 19:150-7.

38. Boerma WG, van der Zee J, Fleming DM. Service profiles of general practitioners in Europe. European GP Task Profile Study. Br J Gen Pract 1997;47: 481-6.

39. Forrest CB. Primary care gatekeeping and referrals: effective filter or failed experiment? BMJ 2003;326: $692-5$.

40. Eggleston KN. Health care for 1.3 billion: an overview of China's health system. Asia Health Policy Program working paper 28. Stanford, CA: Stanford University; 2012. Available from: http://www.cpc. unc.edu/projects/china/publications/1350. Accessed January 14, 2016.

41. Zhao G. Disorder causes difficult medical care seeking and expensive instruments cause high medical costs. China Health Ins 2014;(12):24-5.

42. Chun CB, Kim SY, Lee JY, Lee SY. Republic of Korea health system review. Health Syst Transit 2009;11. Available from: http://www.euro.who.int/ __data/assets/pdf_file/0019/101476/E93762.pdf. Accessed January 14, 2016.

43. Wu T-Y, Majeed A, Kuo KN. An overview of the healthcare system in Taiwan. London J Prim Care (Abingdon) 2010;3:115-9.

44. Health service delivery profile. Japan. 2012. Geneva: World Health Organization; 2012. Available from: http://www.wpro.who.int/health_services/service_ delivery_profile_japan.pdf. Accessed January 14, 2016.

45. Wang M-J, Lin S-P. Study on doctor shopping behavior: insight from patients with upper respiratory tract infection in Taiwan. Health Policy 2010;94: 61-7.

46. Macinko J, Starfield B, Erinosho T. The impact of primary healthcare on population health in low-and middle-income countries. J Ambul Care Manage 2009;32:150-71.

47. Starfield B, Shi L, Grover A, Macinko J. The effects of specialist supply on populations' health: assessing the evidence. Health Aff (Millwood) 2005;Suppl Web Exclusives:W5-97-107.

48. Starfield B, Chang HY, Lemke KW, Weiner JP. Ambulatory specialist use by nonhospitalized patients in us health plans: correlates and consequences. J Ambul Care Manage 2009;32:216-25.

49. Zhou XD, Li L, Hesketh T. Health system reform in rural China: voices of healthworkers and serviceusers. Soc Sci Med 2014;117:134-41.

50. Zheng D. On the difficulties and counter measures in implementing public welfare nature of public hospitals from the perspective of new health reform program. Chin J Health Policy 2009;(8):22-7.

51. $\mathrm{Xu} \mathrm{W}$, Bo N, Yin $M$. On the reasons and the harm of current excessive expansion of public hospitals in China. Med. and Philos. 2014;(17):60-3.

52. National Health and Family Planning Commission PRC. Strictly control the fast expansion of public hospital scale. Beijing: National Health and Family Planning Commission of the People's Republic of China; 2014.

53. National Health and Family Planning Commission PRC. The outline of national healthcare system planning (2015 to 2020). Beijing: National Health and Family Planning Commission of the People's Republic of China; 2014.

54. Jiang RS. Development and prospect of general practice in China. J Kunming Med Univ. 2012;10: $1-3$.

55. Wang Y, Zhang S, Liu B, Gong F, Dong Z. The willingness of medical students in designated programs to work in primary care and its influencing factors. Chin Gen Pract 2014;17:2996-3000.

56. Du J, Lu X, Wang Y, et al. Mutual referral: a survey of GPs in Beijing. Family Practice. 2012;29:441-7.

57. Andersen R, Newman JF. Societal and individual determinants of medical care utilization in the United States. Milbank Mem Fun Q Health Soc 1973;51:95-124. 